
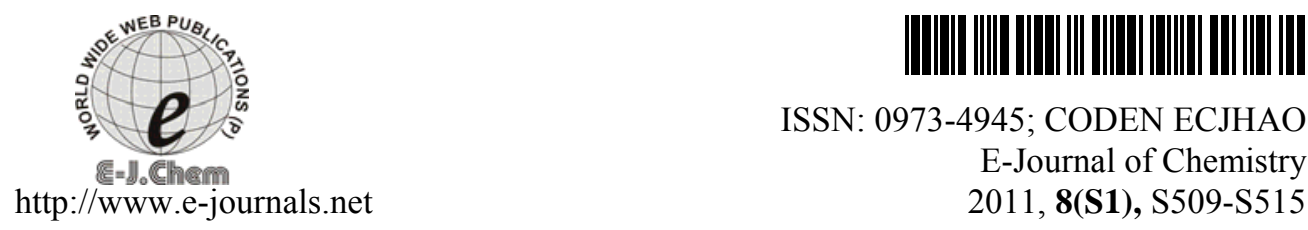

ISSN: 0973-4945; CODEN ECJHAO

E-Journal of Chemistry

2011, 8(S1), S509-S515

\title{
Reactive Extraction of L (+) Tartaric Acid by Amberlite LA-2 in Different Solvents
}

\author{
İ. İNCI, Y. S. AŞÇI and A. F. TUYUN** \\ Chemical Engineering Department, Faculty of Engineering \\ İstanbul University, 34320, İstanbul, Turkey \\ *Department of Chemical Engineering, Engineering \& Architecture Faculty, \\ Beykent University, Ayazağa, Istanbul, Turkey \\ isminci@istanbul.edu.tr
}

Received 4 April 2011; Accepted 7 June 2011

\begin{abstract}
The extraction of $\mathrm{L}(+)$ tartaric acid from aqueous solutions by amberlite LA-2 is a secondary amine mixture in different diluent solvents. Extraction equilibria of $\mathrm{L}(+)$ tartaric acid by amberlite LA-2 in 1-octanol, cyclohexane, isooctane, hexane, methyl isobutyl ketone (MIBK) solvents at temperature $298.15 \mathrm{~K}$ have been measured. The batch extraction experiments distribution coefficients $(D)$, loading factors $(Z)$ and extraction efficiency $(E)$ were calculated. The maximum removal of $\mathrm{L}(+)$ tartaric acid is $91 \%$ with MIBK and 0.92 mol. $\mathrm{L}^{-1}$ initial concentration of Amberlite LA-2.
\end{abstract}

Keywords: Extraction, L(+) tartaric acid, Amberlite LA-2

\section{Introduction}

Organic acids are important chemicals, as the oxygen of the biomass is placed in a form that is useful for many reaction with important products. The conventional method for recovering hydroxycarboxylic acid, as $\mathrm{L}(+)$ tartaric acid is, from fermentation solutions, is common precipitation process. This way of recovery is costly and unfriendly to the environment. $\mathrm{L}(+)$ tartaric acid is the dextro form of 2,3 dihydroxysuccinic acid. It has been known as pottasium salt, whih occurs in grapes. In the fermentation of grape juice, the salt deposits in the fermentataion equipment ${ }^{1}$.

The crystalized L $(+)$ tartaric acid was this potassium salt obtained from such fermentation residues by Scheele in 1769. Tartaric acid is used in the preparation of carbonated drinks, especially grape flavored. It is widely employed in the effervesent tablets and powders,. frequently mixed with citric acid. Carboxylic acids can be obtained by fermentation ${ }^{2}$. 
As their hydrophilic nature, hydroxycarboxylic acids are not extractable by conventional organic solvents; so, for recovering of organic acids from aqueous solutions reactive extraction has been considered ${ }^{3,4}$. Aliphatic secondary and tertiary amines, with $\mathrm{C}_{7}-\mathrm{C}_{10} / \mathrm{C}_{12}$ alkyl groups (TAA), have been proposed and used as suitable extractants for these acids. The amine extractants are dissolved in a diluent that dilutes the extractant to the desired concentration and controls the viscosity and density of the solvent phase. It has been found that, in the systems with the same acid and the same amine, the type of solvent and the composition of extraction mixture affect the extraction equilibrium ${ }^{5,6}$.

Polar diluents have been shown to be more suitable than inert ones (nonpolar), due to the higher distributions ${ }^{8}$. Active polar and proton-donating diluents as alcohols have been shown to be the most convenient diluents for amines, because they give the highest distributions resulting from the formation of solvates through specific hydrogen bonding between the proton of the diluent and the acid-amine complex ${ }^{7-9}$. Some researchers propose the formation of acid-amine complexes of only one type $(1,1)$ or $(1,2)$, depending on the diluent while the others suggest the formation of at least two ${ }^{4,7}$.

It has been found that diluents, especially those with functional groups can influence the extraction behaviour of amine significantly. The stoichiometry of solute:amine complex, loading of amine as well as the third phase formation are affected by the diluent. The effect of diluent can be understood by means of ability to solvate to organic phase species, thus it is required to distinguish between general solvation from electrostatic, dispersion or other type of forces and specific solvation due to hydrogen bonding ${ }^{8}$.The obtained acid:amine complexes are supposed to be stabilizied due to the hydrogen bonding with the diluent ${ }^{5-9}$.

Many researchers have investigated the extraction of different carboxlic acids by amine extractants in different diluting solvents ${ }^{10-17}$. But, there are not sufficient data about extraction of $\mathrm{L}(+)$ tartaric acid by Amberlite LA-2 in diluents that used in this work. The aim of this work is to investigate the extraction of $\mathrm{L}(+)$ tartaric acid from aqueous solutions by Amberlite LA-2 in five different solvents (1-octanol, cyclohexane, isooctane, hexane, methyl isobutyl ketone (MIBK) in a wide range of amine concentration $(0.18-0.92)$ mol. $\mathrm{L}^{-1}$.

Extraction experiments were made with amberlite LA-2 dissolved in the diluents of various types - ketone (MIBK), different alkanes (isooctane, cyclohexane, hexane), alcohol (1-octanol). From the results of batch extraction experiments distribution coefficients were calculated. Distribution coefficients, extraction efficiency and variation of loading factors were obtained. They were used to obtain conclusions about the stoichiometry of complex formation.

\section{Theoretical}

The extraction of $\mathrm{L}(+)$ tartaric acid $\left(\mathrm{H}_{2} \mathrm{~A}\right)$ with Amberlite LA-2 $\left(\mathrm{R}_{2} \mathrm{NH}\right)$ can be described by this reaction

$$
i \mathrm{HA}+j *\left(\mathrm{R}_{2} \mathrm{~N}\right)_{\mathrm{j}}=*(\mathrm{HA})_{i} \cdot\left(\mathrm{R}_{2} \mathrm{~N}\right)_{\mathrm{j}} \mathrm{i}=1, \mathrm{p}, \mathrm{j}=1, \mathrm{q}
$$

Where HA represents the nondissociated part of the acid in the aqueous phase and organic phase species are shown with $\left(^{*}\right)$. Because of no overloading of amine has been observed is expected to be lesser than or equal to $\mathrm{j}$ for any $\mathrm{p}$ and $\mathrm{q}$. Eqn. 1 can be characterised by the overall thermodynamic extraction efficiency.

$$
{ }^{*} \mathrm{~K}_{\mathrm{ij}}=*\left[*(\mathrm{HA})_{i} \cdot\left(\mathrm{R}_{2} \mathrm{~N}\right)_{\mathrm{j}} /[\mathrm{HA}]^{\mathrm{i} *}\left[\mathrm{R}_{2} \mathrm{~N}\right]^{\mathrm{j}}\right.
$$


Where square brackets means activities. The loading of the amine extractant, $\mathrm{Z}$ is given as the total concentration of acid in the organic phase, divided by the total concentration of amine in organic phase ${ }^{6}$. The equation for the loading, $\mathrm{Z}$, can be writen as follows,

$$
\mathrm{Z}=\mathrm{C}_{a} / \mathrm{C}_{\mathrm{e}} \text {, org }
$$

Distribution coefficients for $\mathrm{L}(+)$ tartaric acid extracted from water into organic phase were given as,

$$
\mathrm{D}=\mathrm{C}_{a, \text { org }} / \mathrm{C}_{\mathrm{a}}
$$

The efficiency of extration, $\mathrm{E}$ is determinated as

$$
\mathrm{E}=\left(1-\left(\mathrm{C}_{a} / \mathrm{C}_{\mathrm{ao}}\right)\right) \times 100
$$

Where $\mathrm{C}_{a}$ is concentration of acid in the aqueous phase, $\mathrm{C}_{a o}$ is initial concentration of acid, $\mathrm{C}_{\mathrm{e}}$, org is concentration of amine in the organic phase and $\mathrm{C}_{a \text {,org }}$ is concentration of acid in the organic phase $\mathrm{e}^{3-6}$.

\section{Experimental}

Amberlite LA-2, L (+) tartaric acid and solvents were obtained from Merck Company. Amberlite LA-2 was used a mixture of straight-chain secondary amine mixture (M=374 g / mol). All chemicals were used without further purification.

$\mathrm{L}(+)$ tartaric acid were dissolved in water to obtain the solutions with initial concentrations of acid 10.35 mass $\%\left(0.77\right.$ mol. $\left.\mathrm{L}^{-1}\right)$. Organic phases were prepared by the dissolution Amberlite LA-2 in the solvents to prepare solutions with approximately constant concentrations (0.92 mol. $\left.\mathrm{L}^{-1}, 0.74 \mathrm{~mol} . \mathrm{L}^{-1}, 0.55 \mathrm{~mol} . \mathrm{L}^{-1}, 0.37 \mathrm{~mol} . \mathrm{L}^{-1}, 0.18 \mathrm{~mol} . \mathrm{L}^{-1}\right)$.

For extraction experiments, same volumes of an aqueous $\mathrm{L}(+)$ tartaric acid solution and an organic solution of amine were mixed in glass flasks in shaker bath at $25^{\circ} \mathrm{C}$ for 4 $\mathrm{h}$, which preliminary experiments demonstrated to be a sufficient time for equilibration. This mixture was kept in a bath for another $(10-12)$ h to reach full separation of phases.

The concentration of the acid in the aqueous phase was determined by titration with Schott titroline easy modul-2 otomatic titrator and aqueous $0.1 \mathrm{~N}$ sodium hydroxide (relative uncertainty: $1 \%$ ). Acid analysis was checked against a material balance ${ }^{17}$.

\section{Results and Discussion}

Table 1 shows results of the experimental investigation. The concentrations of amberlite LA-2 in solvents were between 0.18 mol. $\mathrm{L}^{-1}$ and $0.92 \mathrm{mol.} \mathrm{L}^{-1}$. The concentration of $\mathrm{L}(+)$ tartaric in the initial aqueous phase was 0.77 mol. $\mathrm{L}^{-1}(=10$ mass \%).

The extraction data equilibrium of $\mathrm{L}(+)$ tartaric acid between water and amberlite LA-2 dissolved in 1-octanol, cyclohexane, isooctane, hexane, methyl isobutyl ketone (MIBK) were given in Table 1. It is possible to see from Table 1 that considerable amount of L $(+)$ tartaric acid can be extracted by Amberlite LA-2 from aqueous solutions. The amount of acid extractable depends on the Amberlite LA-2 amount and type of diluting solvent. The maximum extraction of $\mathrm{L}(+)$ tartaric acid is $91.09 \%$ with MIBK at 0.92 mol. $\mathrm{L}^{-1}$ initial concentration of amberlite LA-2. The acid concentration in water at equilibrium $\left(C_{a}\right)$ decreases from $0.702 \mathrm{~mol} . \mathrm{L}^{-1}$ to $0.06 \mathrm{~mol} . \mathrm{L}^{-1}$ with increasing in the amount of amberlite LA-2 from $0.18 \mathrm{~mol} . \mathrm{L}^{-1}$ to $0.92 \mathrm{~mol} . \mathrm{L}^{-1}$. Distribution coefficient increases from 0.09 to 10.66 with increasing in the concentration of amberlite LA-2 from 0.18 mol. $\mathrm{L}^{-1}$ to $0.92 \mathrm{~mol} . \mathrm{L}^{-1}$ for MIBK. LA-2. 
Table 1. Experimental results of the extraction of $\mathrm{L}(+)$ tartaric acid with amberlite LA-2 / individual diluting solvents.

\begin{tabular}{ccccccc}
\hline Diluent & $\begin{array}{c}\mathrm{C}_{\mathrm{e} \text { org }} \\
\left.\text { mol. } \mathrm{L}^{-1}\right)\end{array}$ & $\begin{array}{c}\mathrm{C}_{a} \\
\mathrm{mol.L}^{-1}\end{array}$ & $\begin{array}{c}\mathrm{C}_{a \text { org }} \\
\text { mol. }^{-1}\end{array}$ & $\mathrm{D}$ & $\mathrm{Z}$ & $100 \mathrm{E}$ \\
\hline Cyclohexane & 0.19 & 0.68 & 0.09 & 0.13 & 0.47 & 11.18 \\
& 0.37 & 0.51 & 0.26 & 0.50 & 0.69 & 33.29 \\
& 0.56 & 0.34 & 0.43 & 1.29 & 0.79 & 56.32 \\
& 0.74 & 0.25 & 0.52 & 2.13 & 0.71 & 68.02 \\
Isooctane & 0.93 & 0.13 & 0.65 & 5.16 & 0.70 & 83.76 \\
& 0.19 & 0.66 & 0.11 & 0.16 & 0.58 & 13.91 \\
& 0.37 & 0.50 & 0.27 & 0.55 & 0.74 & 35.50 \\
MIBK & 0.56 & 0.36 & 0.41 & 1.16 & 0.75 & 53.64 \\
& 0.74 & 0.22 & 0.55 & 2.49 & 0.74 & 71.36 \\
& 0.93 & 0.13 & 0.64 & 5.13 & 0.70 & 83.67 \\
& 0.19 & 0.70 & 0.07 & 0.10 & 0.36 & 8.75 \\
& 0.37 & 0.52 & 0.25 & 0.48 & 0.68 & 32.49 \\
& 0.56 & 0.36 & 0.41 & 1.14 & 0.74 & 53.16 \\
1-octanol & 0.74 & 0.17 & 0.60 & 3.47 & 0.81 & 77.61 \\
& 0.93 & 0.07 & 0.70 & 10.66 & 0.76 & 91.43 \\
& 0.19 & 0.66 & 0.11 & 0.55 & 0.58 & 14.01 \\
& 0.37 & 0.52 & 0.25 & 0.16 & 0.67 & 32.19 \\
& 0.56 & 0.36 & 0.41 & 0.48 & 0.74 & 52.87 \\
& 0.74 & 0.20 & 0.57 & 1.12 & 0.77 & 73.58 \\
& 0.93 & 0.12 & 0.65 & 2.79 & 0.71 & 84.84 \\
Hexane & 0.19 & 0.68 & 0.09 & 0.13 & 0.46 & 11.07 \\
& 0.37 & 0.52 & 0.26 & 0.50 & 0.69 & 33.09 \\
& 0.56 & 0.38 & 0.39 & 1.02 & 0.71 & 50.55 \\
& 0.74 & 0.24 & 0.53 & 2.18 & 0.71 & 68.58 \\
& 0.93 & 0.14 & 0.63 & 4.49 & 0.68 & 81.78 \\
\hline
\end{tabular}

Table 2. Distribution of $\mathrm{L}(+)$ tartaric acid between solvents and water.

\begin{tabular}{ccccc}
\hline Diluent & $\begin{array}{c}\mathrm{C}_{a} \\
\mathrm{mol.L}^{-1}\end{array}$ & $\begin{array}{c}\mathrm{C}_{a} \text { org } \\
\mathrm{mol.L}^{-1}\end{array}$ & $\mathrm{D}$ & $100 \mathrm{E}$ \\
\hline Cyclohexane & 0.72 & 0.05 & 0.06 & 6.11 \\
Isooctane & 0.71 & 0.07 & 0.09 & 8.33 \\
MIBK & 0.75 & 0.01 & 0.02 & 2.14 \\
1-octanol & 0.71 & 0.06 & 0.09 & 8.33 \\
Hexane & 0.74 & 0.03 & 0.04 & 3.96 \\
\hline
\end{tabular}

It is possible to explain extraction of carboxylic acids with amines by the formation of acid: amine complexes, that effected by the diluents in different way. Solvation of the complex by the diluents is the most important factor that in the extraction of acid. The interactions between the complex and diluent can be separated into general solvation and specific interactions of the diluent with the complex. Polar diluents have been shown to be more suitable diluents than inert ones (no polar), because of the higher distributions. But in the extraction of L (+) tartaric acid by secondary amine mixture used in this study has not been found such an effect. As a result of this study, it canbe sad that polarity of diluent is not important in extraction of L ( + ) tartaric acid extraction by secondary amine mixture. 
Figure 1 shows the effect of organic solvents on the extraction of L $(+)$ tartaric acid from aqueous solutions. In this figure the extraction power of amberlite LA-2 - diluents mixture changes with increasing initial concentration of amberlite LA-2 in the organic phase. Figure 2 presents the effect of amberlite LA-2 concentration on loading. The loading curve is a plot of $Z$ vs. amine concentration. Overloading (loading greater then unity), indicates that complexes with more than one acid per amine have been formed. With all of the solvents overloading can not be observed.

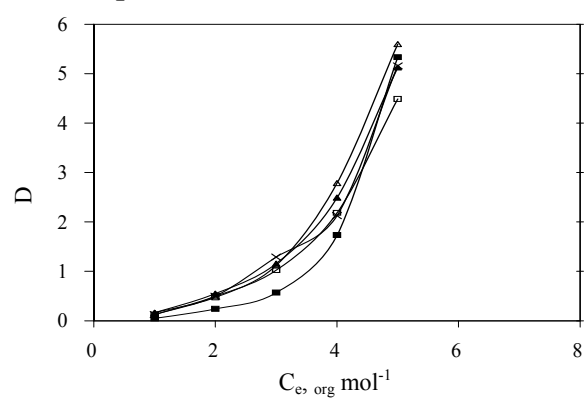

Figure 1. Variation of $D$ with concentration of Amberlite LA-2 in different individual diluting diluents at $25{ }^{\circ} \mathrm{C}$. ( $\Delta, 1$-octanol; MIBK; $\boldsymbol{\Delta}$, Isooctane; $\mathrm{x}$, Cyclohexane; $\square$, Hexane)

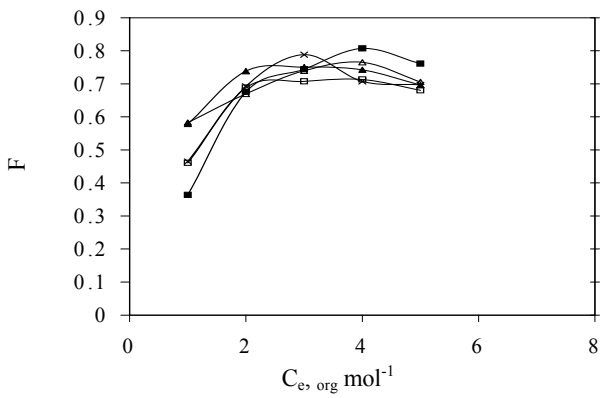

Figure 2. Variation of loading factors with concentration of Amberlite LA-2 in different diluting diluents at $25{ }^{\circ} \mathrm{C} .(\Delta, 1-$ octanol; $\mathbf{-}$ MIBK; $\boldsymbol{\Delta}$, Isooctane; $\mathrm{x}$, Cyclohexane; $\square$, Hexane)

Systems include one amine per complex, there is no effect of total amine concentration on the loading. In this work, there is not any this type of loading curve. If there is more than one amine per complex loading increase with increasing amine concentration. Systems that exhibit aggregation, formation of complexes with large numbers of acid and amine molecules, exhibit an abrupt increase in loading. In this work, all of the solvents (isooctane, hexane, MIBK, 1- octane, cyclohexane) exhibit increase in loading with increasing amine concentration, indicating that complexes include more than one amine per complex. Also, this result confirmed that MIBK and hexane exhibit an abrupt increase in loading indicating formation of complexes with large numbers of acid and amine molecules ${ }^{18,19}$.

Figure 3 and Table 3 presents the effect of the initial concentration of $\mathrm{L}(+)$ tartaric acid on the distribution coefficient. As the concentration increased, the distribution coefficient decreased. It can be seen that the extraction power of amberlite LA-2 decreases with increasing initial concentration of $\mathrm{L}(+)$ tartaric acid the aqueous phase.

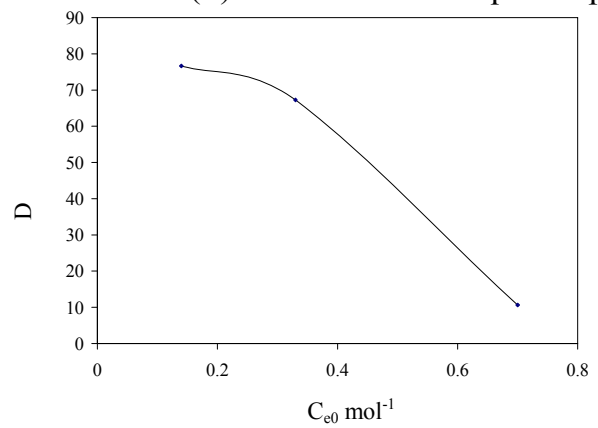

Figure 3. Effect of the initial acid concentration on $\mathrm{L}(+)$ tartaric acid distribution between water and amberlite LA-2. 
Table 3. Effect of initial acid concentration on the extraction of $\mathrm{L}(+)$ tartaric acid

\begin{tabular}{ccccccc}
\hline $\begin{array}{c}\text { Initial Acid } \\
\text { Concentration, mol.L-1 }\end{array}$ & $\begin{array}{c}\mathrm{C}_{\mathrm{e} \text { org }}, \\
\text { mol.L }^{-1}\end{array}$ & $\begin{array}{c}\mathrm{C}_{\mathrm{a}}, \\
\text { mol.L }^{-1}\end{array}$ & $\begin{array}{c}\mathrm{C}_{\mathrm{a} \text { org }}, \\
\text { mol.L }^{-1}\end{array}$ & $\mathrm{D}$ & $\mathrm{Z}$ & $100 \mathrm{E}$ \\
\hline 0.14 & 0.92 & 0.002 & 0.14 & 76.65 & 0.18 & 99.67 \\
0.34 & 0.92 & 0.005 & 0.33 & 67.26 & 0.36 & 99.35 \\
0.77 & 0.92 & 0.066 & 0.70 & 10.66 & 0.76 & 91.43 \\
\hline
\end{tabular}

The distribution data of $\mathrm{L}(+)$ tartaric acid between water and solvents used in this study (1-octanol, cyclohexane, isooctane, hexane, methyl isobutyl ketone (MIBK) are presented in Table 2 and shown in Figure 4.

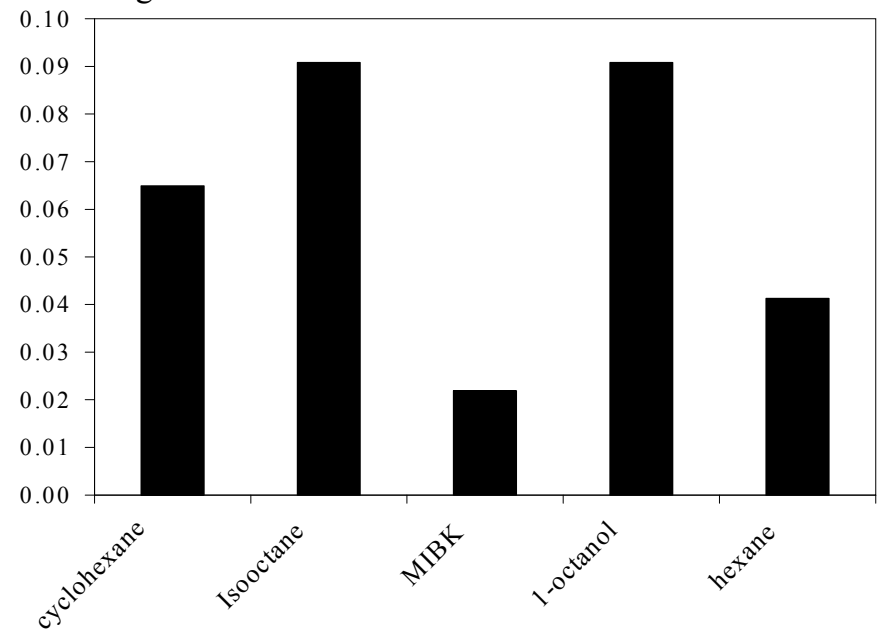

Figure 4. Distribution coefficients of $\mathrm{L}(+)$ tartaric acid between water and solvents used in this study.

\section{Conclusion}

This investigation is given the extraction data of $\mathrm{L}(+)$ tartaric acid from aqueous solutions by Amberlite LA-2 and different solvent systems. It is concluded that the extractability of L $(+)$ tartaric with Amberlite LA-2 with high especially with polar solvents such as MIBK and 1-octanol. The maximum removal of $\mathrm{L}(+)$ tartaric acid is $91 \%$ with MIBK and 0.92 mol. $\mathrm{L}^{-}$ ${ }^{1}$ initial concentration of Amberlite LA-2. The maximum extraction efficiencies for diluents used at maximum Amberlite LA -2 concentration are determinated as, MIBK $>1$-octanol $>$ isooctane $>$ cyclohexane $>$ hexane.

\section{References}

1. Grayson M, Kirk-Othmer Encyclopedia of Chemical Technology, $3^{\text {rd }}$ Ed., John Wiley \& Sons Inc., 1978.

2. Chaikorski A A, Niklskii B P and Mikhailov B A, Sov Radiochem., 1966, 8, 152 158.

3. Schlichting E, Halwachs W and Schügerl K, Chem Eng Process., 1985, 19, 317-328.

4. Vanura P, Kuca L, Collect Checz Chem Commun., 1976, 41, 2857 - 2877.

5. Wennersten R, J Chem Technol Biotechnol., 1983, 33, 85-94.

6. Kertes A S and King C J, Biotechnol. Bioeng., 1986, 28, 269 -282.

7. Tamada J A, Kertes A S and King C J, Ind Eng Chem Res., 1990, 29, 1319-1326. 
8. Bizek V, Horacek J and Kousova A , Herberger A and Prochazka J, Chem Eng Sci., 1992, 47, 1433-1440.

9. Yang S T, White S A and Hsu S T, Ind Eng Chem Res., 1991, 30, 1335 -1342.

10. Wasewar K L, Heesink A B M, Versteeg G F and Pangarkar V G, J Biotechnol., 2002, 97, 59-68.

11. Uslu H, Fluid Phase Equilibria, 2007, 253 , 12-18.

12. Aşçı Y S and İnci İ, Chem Eng J, 2009, 155, 784-788.

13. Qin W, Yaohong Z, Zhenyui L and Youyuan D, J Chem Eng Data, 2003, 48, 430434.

14. Kyuchoukov G, Labaci A, Albet J and Molinier J, Ind Eng Chem Res., 2006, 45, 503-510.

15. Hong Y K and Hong W H, Sep Pur Technol., 2005, 42,151-157.

16. Wang Y D, Li Y X, Li Y, Wang J Y, Li Z Y and DaiY Y, J Chem Eng Data, 2001, 46, 831-837.

19. Kirsch T and Maurer G, Ind Eng Chem Res., 1996, 35, 1722-1735.

20. Aşçı Y S and İnci İ, J Chem Eng Data, 2009, 54 , 2791-2794.

21. Aşçı Y S and İnci İ, J Chem Eng Data, 2010, 55, 847-851. 


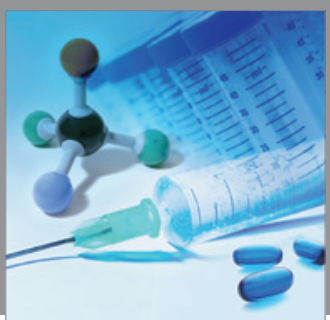

International Journal of

Medicinal Chemistry

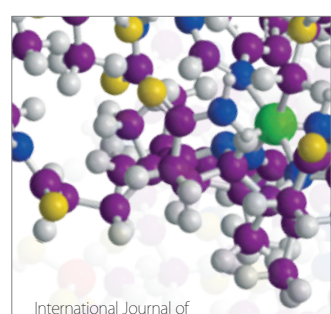

Carbohydrate Chemistry

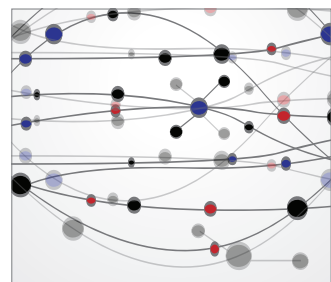

The Scientific World Journal
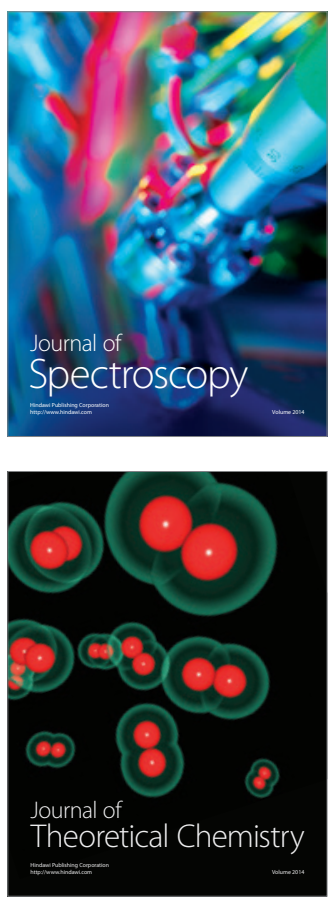
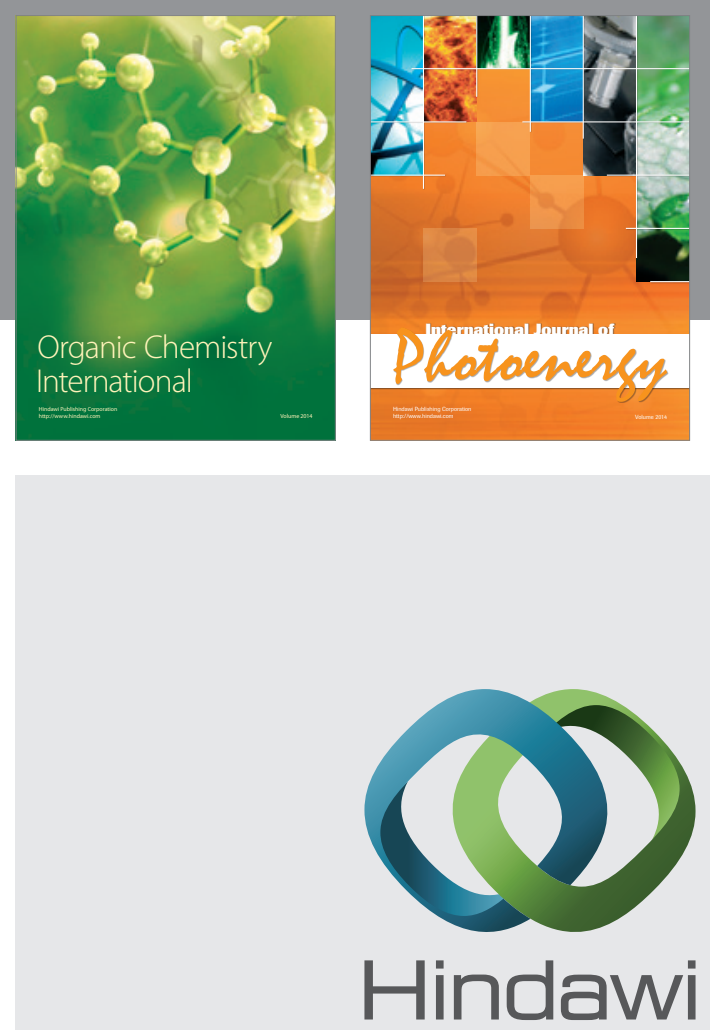

Submit your manuscripts at

http://www.hindawi.com
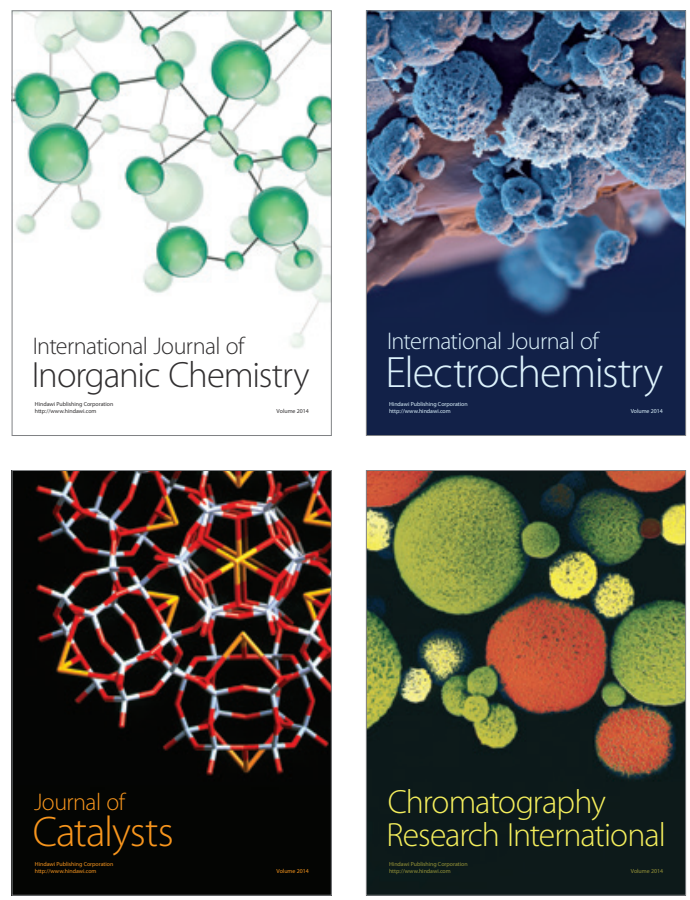
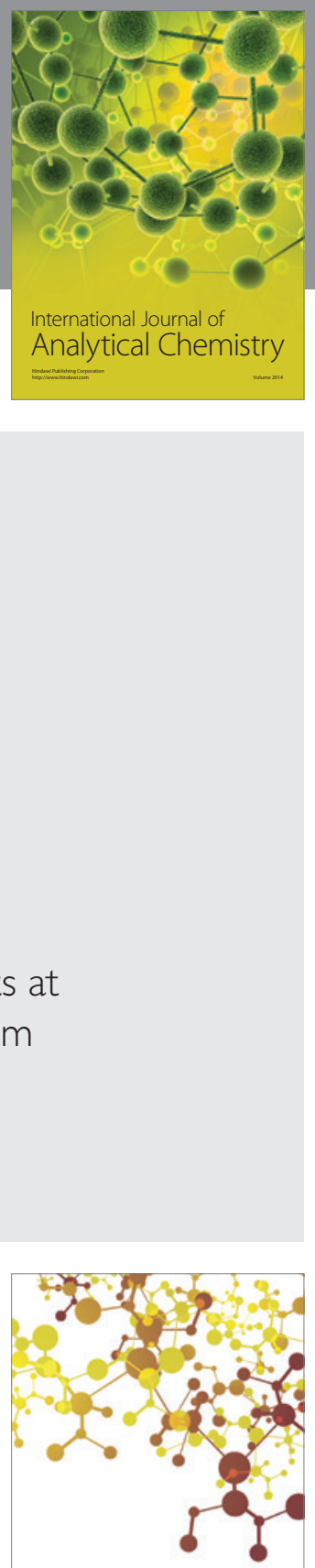

Journal of

Applied Chemistry
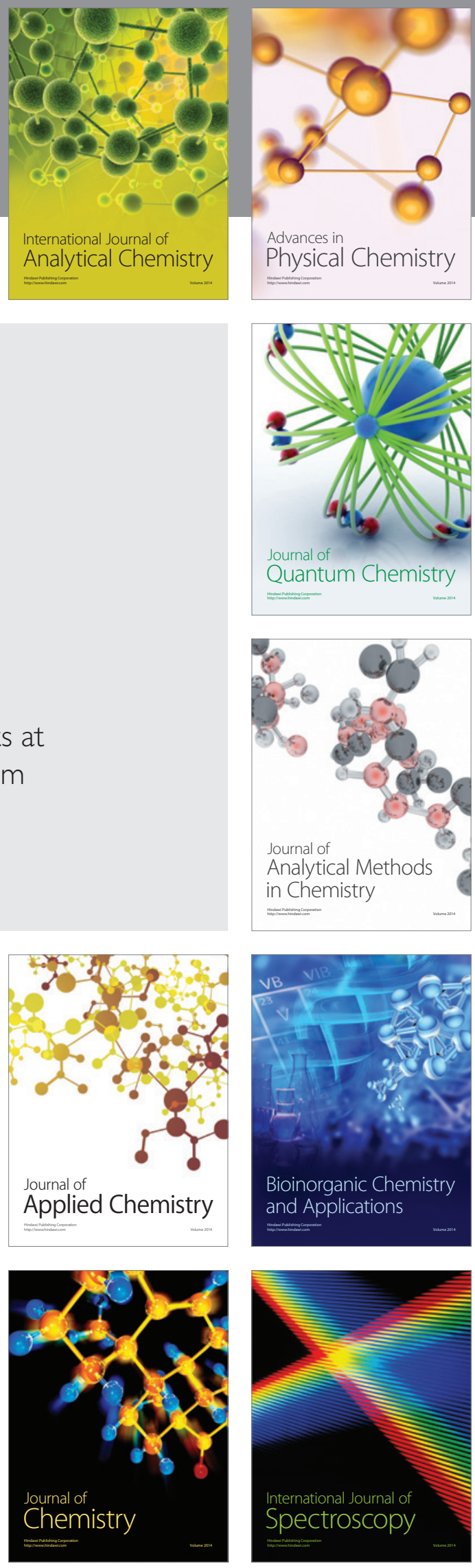